\title{
Effect of Scandium Doping on the Corrosion Resistance and Mechanical Behavior of Al-3Mg Alloy in Neutral Chloride Solutions
}

\author{
Zaki Ahmad ${ }^{1}$, Abdul Aleem B. Jabbar ${ }^{1}$, Kachalla Abdullahi' ${ }^{1}$ Mohammad Abbas ${ }^{2}$ \\ ${ }^{1}$ Mechanical Engineering Department, King Fahd University of Petroleum \& Minerals, Dhahran, Saudi Arabia; ${ }^{2}$ Cathodic protection \\ Engineer, Arabial Petrochemical Company, Jubail, Saudi Arabia. \\ E-mail:\{ahmadz, abaleem\}@kfupm.edu.sa, abbasm@petrokemya.sabic.com
}

Received July $24^{\text {th }}, 2010$; revised January $31^{\text {st }}, 2011$; accepted February $28^{\text {th }}, 2011$.

\begin{abstract}
Scandium addition significantly alters the corrosion resistance and mechanical strength of Al-3 Mg alloys. The addition of $0.3 \%-0.4 \%$ scandium with $0.14 \%$ zirconium has a beneficial effect on the corrosion resistance of the alloy under smoothly stirred condition. Addition of $0.3 \%$ Sc significantly suppresses corrosion under dynamic flow conditions. It also creates an optimal strengthening effect on the alloys. The corrosion resistance is attributed to the strong passive layer of $\mathrm{Sc}_{2} \mathrm{O}_{3}$ formed on the ultrafine coherent precipitates of $\mathrm{Al}_{3} \mathrm{Sc}$. A strong evidence of the pinning of grain boundaries by coherent nano $\mathrm{Al}_{3} \mathrm{Sc}$ precipitates is responsible for the strengthening effect.
\end{abstract}

Keywords: Corrosion, Polarization, Passive, Pitting, Strengthening Effect, Pinning, Grain Boundaries, Precipitates, Films, Passive Layers

\section{Introduction}

Scandium addition has a strong influence on the properties of aluminum and aluminum alloys. Aluminum alloys doped with scandium have shown improved mechanical strength, hot cracking resistance, weld strength and age hardening response [1-4].

Scandium is a strong modifier of a cast grain structure which makes it possible to obtain continuously cast billed with a non-dendrite structure. The effect of $\mathrm{Al}_{3}$ $\left(\mathrm{Sc}_{1-\mathrm{x}} \mathrm{Zr}_{\mathrm{x}}\right)$ is similar to that of $\mathrm{Al}_{3} \mathrm{Sc}$ because grains can be refined permanently by $\mathrm{Al}_{3}\left(\mathrm{Sc}_{1-\mathrm{x}} \mathrm{Zr}_{\mathrm{x}}\right)$ [5]. The improved hardness is attribution to decreasing dendrites and dispensed secondary phase what inhibit movement of dislocation [6-8]. The optimal concentration of Sc has been reported to be $0.3 \mathrm{wt} \%$ with $\mathrm{Al}-2.5 \mathrm{Mg}$ [9]. In the presence of zirconium a non dendritic structure is formed with lower scandium contents. The formation of coherent $\mathrm{Al}_{3} \mathrm{Sc}$ ultra fine precipitates controls the mechanical properties and corrosion resistance of Al-Mg alloys. The creation of ultra fine precipitates thermodynamically is essential to bring about a significant improvement in high temperature mechanical strength and inhibition of re-crystallization of aluminum alloys. Addition of scandium and zirconium increases the tensile strength by pin- ning of grain boundaries by $\mathrm{Al}_{3}\left(\mathrm{Sc}_{1-\mathrm{x}} \mathrm{Zr}_{\mathrm{x}}\right)$ precipitates [10]. In recent years scandium doping has also been extended to Al MMC's. In aluminum based MMC material with minor additions of Sc was found to be less susceptible to corrosion than the base alloys particularly in neutral and alkaline solutions. At high temperature the composite was characterized by an extended passive region accompanied by lower corrosion rate [11]. The $\mathrm{Al}_{3} \mathrm{Sc}$ precipitates only affect the mechanical strength but significantly suppresses the corrosion rate of Al-Mg alloys. Whereas most work has been focused on mechanical strength there is a lack of published data on the corrosion behavior of Sc doped aluminum alloys. It has been shown that resistance to stress corrosion cracking can be increased by overaging due to un-crystallized grain structure together with non-interconnected nature of grain boundary precipitates [12].

Despite significant progress made in recent decades, not much has been reported to establish a relationship between micrstructure, mechanical strength and corrosion resistance. This paper describes the critical role of ultrafine $\mathrm{Al}_{3}\left(\mathrm{Sc}_{1-\mathrm{x}} \mathrm{Zr}_{\mathrm{x}}\right)$ precipitates on the mechanical mincrostructural and corrosion resistance of $\mathrm{Al}-2.5 \mathrm{Mg}$ alloys and a correlation between the above three parameter. 


\section{Experimental}

\subsection{Fabrication of Alloys}

Five Al-Mg (2.87 - $2.96 \mathrm{Mg})$ alloys were doped with scandium $(0.15-0.9 \mathrm{wt} \%)$ scandium and $0.14 \mathrm{wt} \%$ zirconnium. They were made by induction melting in a recrystalized aluminum crucible under an argon atmosphere. The scandium powder was prevented by air contact by covering with an aluminum foil before dipping in the melt covered by argon. The alloy was chill cast in copper mold. Strips of $2 \mathrm{~mm}$ were obtained by extrusion. The alloy was fabricated by Light Aluminum Metalle, Germany in consultation with the principle author. The chemical composition of the alloy is given in Table 1.

\subsection{Experimental Technique}

\subsubsection{Specimen Preparation}

Specimens in the form of $16 \mathrm{~mm}$ circular discs were used for electrochemical investigations. For recirculation loop test, specimens measuring $70 \times 100 \mathrm{~mm}, 58 \times 100 \mathrm{~mm}$, $48 \times 100 \mathrm{~mm}$ and $40 \times 100 \mathrm{~mm}$ were prepared. All specimens were polished with 400 and $600 \mu \mathrm{m} \mathrm{SiC} \mathrm{paper}$ using de-ionized water as lubricant. Final polishing was done with 0.05 micron aluminum powder. The specimens were rinsed with acetone and washed with de-mineralized water prior to commencement of experiment. Samples in triplicates were used for experiments.

\subsubsection{Weight Loss Studies}

These studies were conducted in accordance with ASTM G5-72 [13]. The samples were exposed for 1360 hours before being re-weighed. The solution was smoothly stirred by a magnetic stirrer. The solution was exposed to open air.

\subsubsection{Electrochemical Studies}

Potentiodynamic polarization, polarization resistance and cyclic polarization studies were conducted to determine the corrosion behavior of the experimental alloys.

1) Potentiodynamic studies were conducted in accordance with ASTM standard G5-87. A software Softcorr III was used to obtain the polarization plots, electrochemical parameters and the corrosion rates [14].

2) The Polarization resistance plots were obtained by applying a controlled potential over a small range of potential $( \pm 25 \mathrm{mV}$ vs SCE$)$ with respect to corrosion potential ( $\mathrm{E}_{\text {corr }}$. The experiments were conducted in accordance with ASTM standards G 59-91 [15].

3) Cyclic polarization measurements were made in accordance with ASTM practice G61-78 [16]. The specimen were polarized for 2 hours at $-1200 \mathrm{mV}$ vs SCE. Polarization was commenced at a scan rate of 100 $\mathrm{mV} / \mathrm{min}$ and continued in a noble direction until a sharp rise in the current occurred $\left(\mathrm{E}_{\mathrm{p}}\right)$. At this point the scan was reversed until the current reached a very small value $\left(E_{p p}\right)$. The protection potential was determined by the intersection of reverse anodic with forward anodic polarization curve.

\subsubsection{Recirculating Loop Studies}

A high velocity PVC loop was constructed to study the effect of velocity. It was comprised of a centrifugal pump $\left(20 \mathrm{~m}^{3} /\right.$ hour$)$, entry and exit valves, manometer, magnetic flow meters and different sizes of specimen holders to create different velocities. A maximum velocity of 3.8 $\mathrm{ms}^{-1}$ was achieved in the loop.

\subsection{Microstructure Examination}

The surface morphology was investigated by low vacuum scanning electron microscope (LVSEM) with and EDS system. A Philips Tecnai F $20 \mathrm{~S}$ Twin TEM was used to conduct surface texture studies. It was fitted with an EDAX energy dispersive X-ray detector with a S-UTW window with $30 \mathrm{~mm}^{2}$ active area. The samples were cut by FIB. The lamella were positioned on a carbon film and TEM examination was made.

\section{Results and Discussion}

As shown by the weight loss studies (Figure 1), all experimental alloys exhibited low rates of corrosion. In particular, alloys 3 and 4 containing ( 0.3 and $0.6 \mathrm{wt} \% \mathrm{Sc})$ showed the lower corrosion rates of ( 0.65 mpy and 0.69 mpy) respectively at the end of 1360 hours of exposure. The rate of corrosion tends to stabilize after 600 hours of exposure after rapid initial fluctuations because of breakdown and repair of oxide film of $\mathrm{Al}_{2} \mathrm{O}_{3}, \mathrm{Sc}_{2} \mathrm{O}_{3}$. After 850 hours, a maximum rate of corrosion (0.529 mpy) was shown by alloy $1(0 \% \mathrm{Sc})$ whereas alloy containing 0.15 and $0.3 \mathrm{wt} \%$ Sc showed relatively low rates of corrosion ( $\approx 0.45 \mathrm{mpy}$ and $0.4 \mathrm{mpy}$ respectively). The corrosion rate of alloys rises during initial exposure, but decreases with increased period of exposure. Alloy 3 and 4 showed lower corrosion rate.

Figure 2 shows a plot of the effect of Sc concentration on the corrosion rates of alloys in $3.5 \% \mathrm{NaCl}$. Corrosion rates were determined by Polarization resistance techniques. Alloy 3 containing $0.3 \mathrm{wt} \% \mathrm{Sc}$ showed the minimum rate of corrosion.

The results obtained were principally from weight loss studies are in agreements with the potentiodynamic polarization resistance studies. From the studies of weight loss studies conducted it may be concluded that alloying addition of 0.3 and $0.6 \mathrm{wt} \% \mathrm{Sc}$ exercises a beneficial influence on the corrosion rate. As shown by Figure 3 optimum lowering of corrosion rates is shown by alloy 3 $(0.3 \mathrm{wt} \% \mathrm{Sc})$, increase in addition of Sc tend to increase the corrosion rate. One of the major concerns of alumi 
Table 1. Composition of Al-Mg-Sc-Zr Alloys.

\begin{tabular}{cccccccccccc}
\hline $\begin{array}{c}\text { Sl. } \\
\text { No. }\end{array}$ & Alloy Name & Si & Fe & Cu & Mn & Mg & Cr & Zn & Ti & Zr & Sc \\
\hline 1 & AlMgZr 0.0-Sc 0.0 & 0.087 & 0.166 & 0.002 & 0.003 & 2.96 & 0.002 & 0.0025 & 0.03 & - & - \\
2 & AlMgZr 0.14-Sc 0.15 & 0.08 & 0.16 & 0.002 & 0.003 & 2.97 & 0.0014 & 0.006 & 0.025 & 0.14 & 0.15 \\
3 & AlMgZr 0.14-Sc 0.3 & 0.09 & 0.15 & 0.002 & 0.003 & 2.95 & 0.0013 & 0.010 & 0.024 & 0.14 & 0.3 \\
4 & AlMgZr 0.14-Sc 0.6 & 0.1 & 0.16 & 0.002 & 0.003 & 2.96 & 0.001 & 0.002 & 0.021 & 0.14 & 0.6 \\
5 & AlMgZr 0.14-Sc 0.9 & 0.092 & 0.16 & 0.001 & 0.004 & 2.87 & 0.001 & 0.007 & 0.028 & 0.14 & 0.9 \\
\hline
\end{tabular}
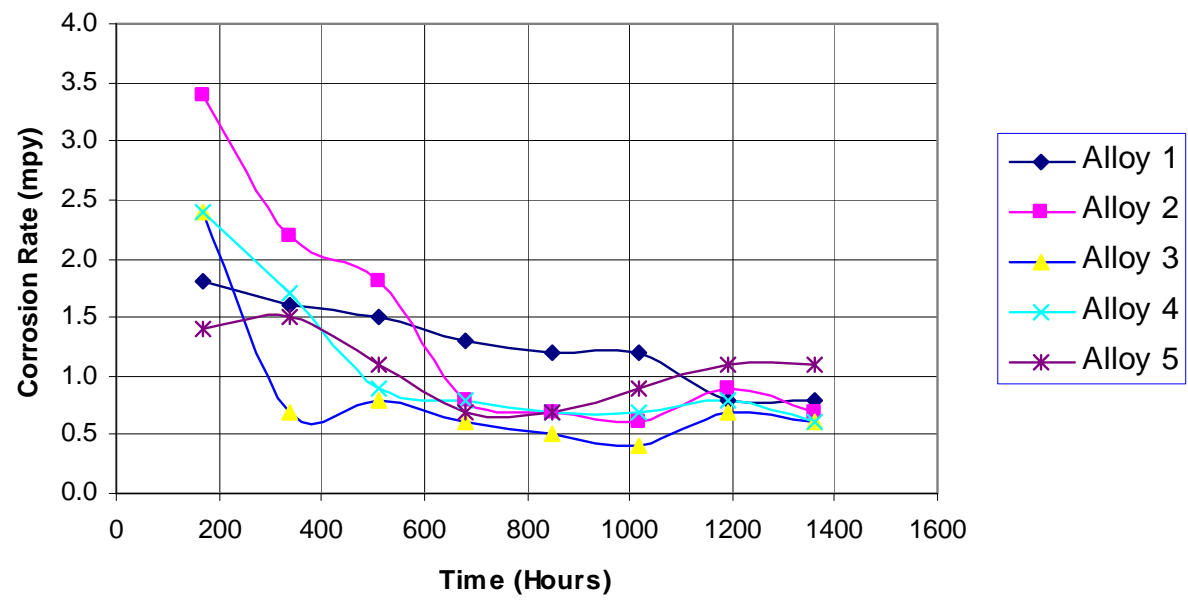

Figure 1. Variation of corrosion rate of Al-Mg-Sc-Zr alloy with exposure time-The corrosion rate of the alloys decreases with increased exposure time.

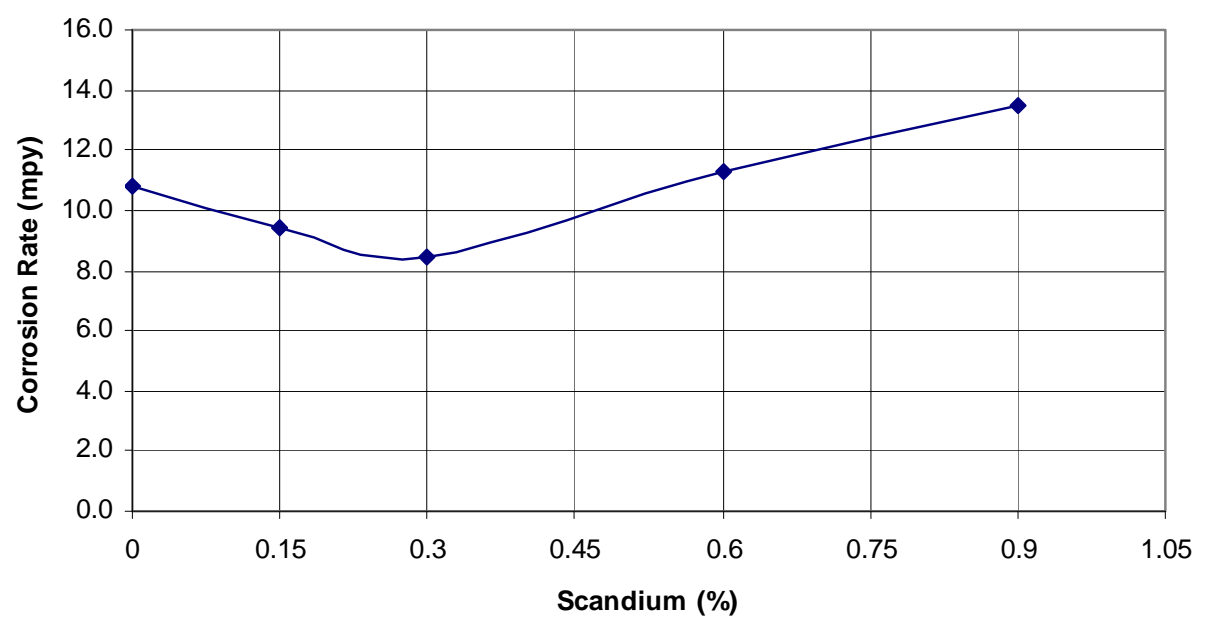

Figure 2. Corrosion rates of Al-Mg-Sc-Zr alloys vs Scandium concentration-The lowest rate of corrosion is shown by alloy 3.

num alloys is the ability to withstand pitting. Cyclic polarization studies were conducted to obtain pitting potentials of the alloy, however small variations in pitting potentials did not allow to conclusively establishing the relative pitting resistance of the alloys as shown by Table 2.
Studies under dynamic flow conditions in a recirculating loop showed that alloy without scandium exhibited the lowest resistance to flow induced corrosion. Increased velocity accelerates the rate of corrosion. Alloy containing $0.3 \mathrm{wt} \% \mathrm{Sc}$ and $0.9 \mathrm{wt} \% \mathrm{Sc}$ show higher resistance to increasing velocity. 


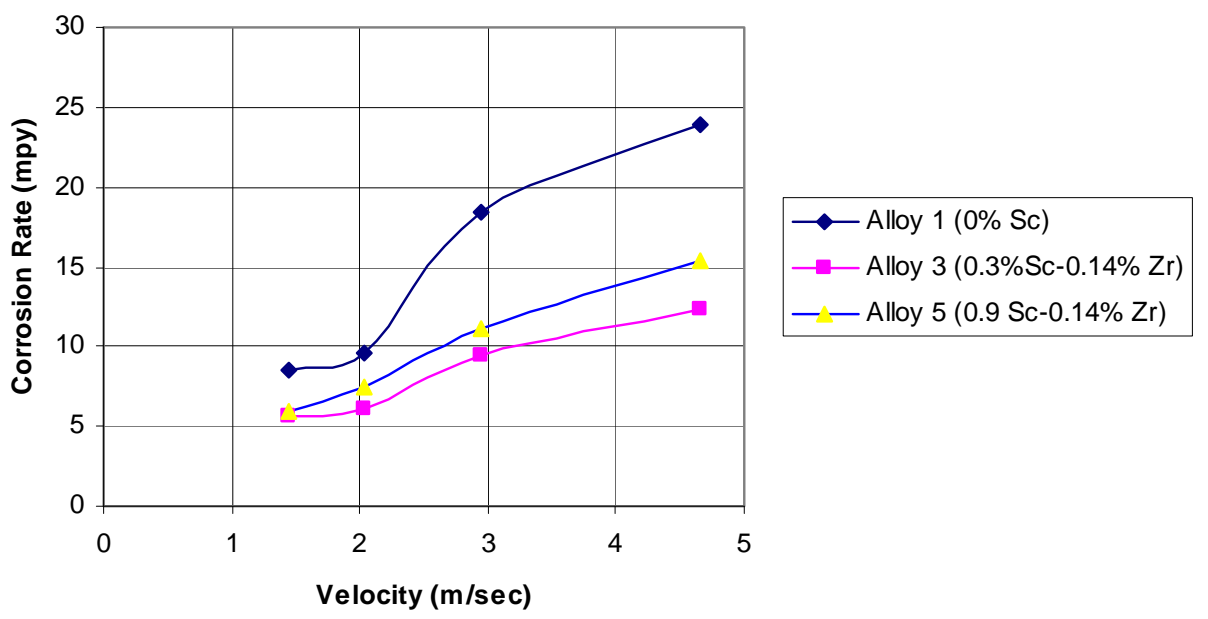

Figure 3. Variation of corrosion rates for alloys 1, 3 and 4 with velocity in recirculating loop exposed to $3.5 \% \mathrm{NaCl}$ solution. The corrosion rate increased with an increase in velocity. Alloy 3 showed a maximum resistance to velocity.

All the different techniques used to determine the corrosion rate showed that an optimum corrosion resistance is shown by alloy 3 containing $0.3 \mathrm{wt} \% \mathrm{Sc}$. It appears that the size of $\mathrm{Al}_{3} \mathrm{Sc}$ precipitate and its distribution primarily controls the corrosion rate as the thickness and uniformity of the protective films of boehmite $\left(\gamma-\mathrm{Al}_{2} \mathrm{O}_{3}\right.$, $\left.\mathrm{H}_{2} \mathrm{O}\right)$ and bayerite $\left(\beta-3 \mathrm{Al}_{2} \mathrm{O}_{3}, \mathrm{H}_{2} \mathrm{O}\right)$ would depend on how uniformly the passivating layer is formed on the surface of the alloy. The rate limiting factor is, however the dissolution of the oxide film formed on the surface. The study of the kinetics of film formation was beyond the scope of this work. The evidence of formation of a needle shaped protective film of boehemite on alloy 2 $(0.3 \mathrm{wt} \% \mathrm{Sc})$ is shown in Figure 4.

Protective film of Boehmite and Bayerlite are known to reduce the corrosion rate of aluminum alloys. The SEM photomicrograph shows the formation of needle shape film of Boehmite in alloy 4. It has been suggested earlier that the corrosion potential of the alloy covered

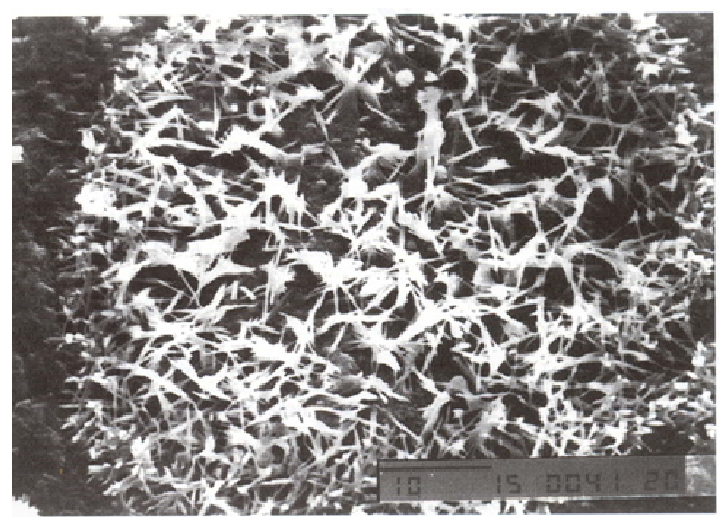

Figure 4. SEM photomicrograph showing the formation of a protective film of boehmite on alloy 4 . The needle shaped structure is seen on the alloy surfaces. with dense low defective layers of aluminum oxyhydroxide and scandium oxide $\left(\mathrm{Sc}_{2} \mathrm{O}_{3}\right)$ increases and the reduction rate of the depolarizer and accordingly the corrosion rate of scandium containing alloy decreases [17] which is consistent with our observations on corrosion rates. It is also reported that whereas aluminum oxyhydroxids (bayerite or boehmite) is formed in the defectivee surface layer because of increased thermodynamic activity, $\mathrm{Sc}_{2} \mathrm{O}_{3}$ which accumulates in the upper part of this layer [18].

From the studies reported above it is established that small concentration of scandium $(0.3-0.6 \mathrm{wt} \%)$ have a beneficial effect on the corrosion resistance, and the protective films of boehemite and $\mathrm{Sc}_{2} \mathrm{O}_{3}$ plays an important role in corrosion resistance. The precipitates of AlSc $\left(\mathrm{Sc}_{1-\mathrm{x}} \mathrm{Zr}_{\mathrm{x}}\right)$ are in the nanorange whereas the precipitates in aluminum alloys like 6061 and 6013 are in the micron range. This has been confirmed by the FEG-SEM microanalytical studies [9]. These particles in contrast offer a lower resistance to corrosion as in bulk alloys. This is

Table 2. Electrochemical parameter obtained from cyclic polarization curves.

\begin{tabular}{cccccc}
\hline $\begin{array}{c}\text { Alloy } \\
\text { Composition }\end{array}$ & $\begin{array}{c}\text { Sc } \\
(\%)\end{array}$ & $\begin{array}{c}\text { Ep } \\
(\mathrm{V})\end{array}$ & $\begin{array}{c}\text { Epp } \\
(\mathrm{V})\end{array}$ & $\begin{array}{c}\text { Ecorr } \\
(\mathrm{V})\end{array}$ & $\begin{array}{c}\text { E1 }= \\
\text { Ep - Ecorr }\end{array}$ \\
\hline $\begin{array}{c}\text { Al-Mg-Zr } 0.0 \\
\quad-S c 0.0\end{array}$ & 0 & -0.715 & -0.783 & -0.84 & 0.127 \\
$\begin{array}{c}\text { Al-Mg-Zr } 0.15 \\
\quad-\mathrm{Sc} 0.15\end{array}$ & 0.15 & -0.721 & -0.795 & -0.786 & 0.065 \\
$\begin{array}{c}\text { Al-Mg-Zr } 0.15 \\
\quad-S c 0.3\end{array}$ & 0.3 & -0.701 & -0.812 & -0.758 & 0.057 \\
$\begin{array}{c}\text { Al-Mg-Zr } 0.15 \\
\quad-S c 0.6 \\
\text { Al-Mg-Zr } 0.15 \\
\quad-S c 0.9\end{array}$ & 0.6 & -0.755 & -0.803 & -0.826 & 0.071 \\
\hline
\end{tabular}


confirmed by recent studies on nanoprecipitates $[9,19]$.

\section{Mechanical Properties and Microstructures}

The mechanical properties of the five experimental alloys are shown in Figure 5. Alloy 1 without Sc addition shows the least strength whereas all Sc doped alloys exhibit higher strengths. The results confirm the role of scandium as a potent strengthener. A maximum increase in strength is obtained on adding $0.3 \mathrm{wt} \% \mathrm{Sc}$ as shown by alloy 3 . Addition of Sc beyond $0.6 \mathrm{wt} \%$ does not create any appreciable gain in the strength. Zirconium addition increases the tensile strength over the zirconium free alloy as shown by Figure 5. It has been suggested that earlier the alloy with Sc contains a higher volume fraction of coherent particles $\mathrm{Al}_{3}(\mathrm{ZrSc})$ particles and the sub grain size of the alloy with scandium is much smaller than the Sc free alloy $[9,18]$. The presence of $\mathrm{Al}_{3} \mathrm{Sc}$ precipitates (FCC) of nano dimensions are responsible for age hardening response, strengthening effects and corrosion resistance as shown by this work.

The tensile strength of the alloys shows optimum strength on addition of $0.3 \mathrm{wt} \% \mathrm{Sc}$, with higher addition, the strength begins to decrease as shown in the figure. The strengthening effect by scandium has been attributed to the Orwan dislocation looping around the nanosize coherent precipitates of $\mathrm{Al}_{3} \mathrm{Sc}_{2}(\mathrm{r}=15-20 \mathrm{~nm})$. The precipitates of $\mathrm{Al}_{3}\left(\mathrm{Sc}_{1-\mathrm{x}} \mathrm{Zr}_{\mathrm{x}}\right)$ pin down the grain and sub grain boundaries and maintain a fine grain size. The TEM bright image field shows the different types of small precipitate (Figure 6) of $\mathrm{Al}_{3} \mathrm{Sc}$.

$\mathrm{Al}_{3}\left(\mathrm{Sc}_{1-\mathrm{x}} \mathrm{Zr}_{\mathrm{x}}\right)$ are observed on the surface of specimens. The nano precipitates and sub grains are observed in the figure. An EDS profile taken shows the peaks of scandium and aluminum. The grain, sub grains and ultra fine spherical and square precipitates are clearly shown in the dark field and inverted signal images in Figure 7.

Figure 8 shows a very clear evidence of pinning of the grain boundaries by the nanosize precipitates of $\mathrm{Al}_{3} \mathrm{Sc}$ as shown by our investingations. The pinning of grain boundaries is a major contribution of $\mathrm{Al}_{3} \mathrm{Sc}$ precipitates to the strengthening mechanism of Sc doped alloy.

The ultra fine coherent precipitates shown in Figures 8 and 9 above would allow the formation of a relatively more uniform oxide film of $\mathrm{Sc}_{2} \mathrm{O}_{3}$ with boehemite in contrast to the larger and incoherent precipitates of boehmite and bayerite observed in Al-Mg alloys. The size of the precipitates not only influences the corrosion behavior but also the mechanical strength of the scandium doped aluminum alloys. More work is needed to explore the properties of the nanosize precipitates and their influence on the mechanical properties and corrosion behavior of scandium doped Al-Mg alloys.

\section{Conclusions}

Based on the investigations conducted following is a summary of conclusion.

1) Scandium addition has a beneficial influence on the corrosion resistance of Al-Mg alloys as shown by weight loss and electrochemical and microanalytical studies.

2) The amount of alloying addition controls the corrosion rate as shown by beneficial effect of 0.3 and 0.4 $\mathrm{wt} \% \mathrm{Sc}$ addition on the corrosion rates under smoothly stirred conditions. Under dynamic conditions, maximum resistance to corrosion is shown by the alloy containing $0.3 \mathrm{wt} \% \mathrm{Sc}$.

3) A passive layer of boehemite is observed to be formed on the alloy surface with a film of $\mathrm{Sc}_{2} \mathrm{O}_{3}$.

4) A maximum improvement in mechanical strength is obtained by adding $0.3 \mathrm{wt} \% \mathrm{Sc}$.

5) The increase in the strength of Al-Mg-Sc alloys is

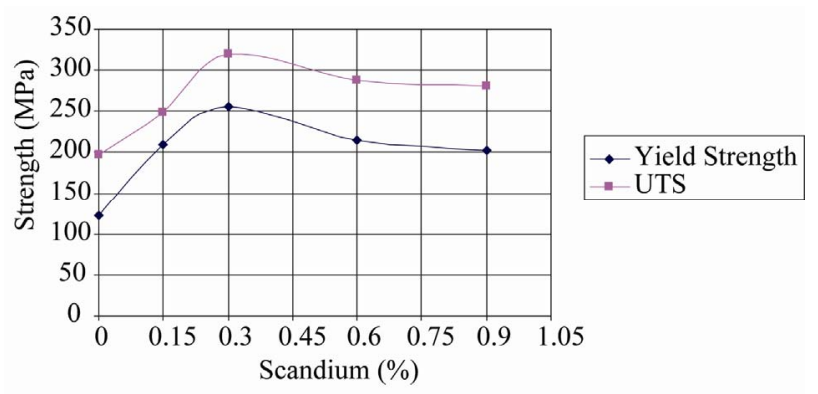

Figure 5. Combined variation of Yield strength and Ultimate strength of Al-Mg-Sc-Zr alloy with \%Sc. The maximum strength is shown by alloy 3 contains $0.3 \mathrm{wt} \% \mathrm{Sc}$.

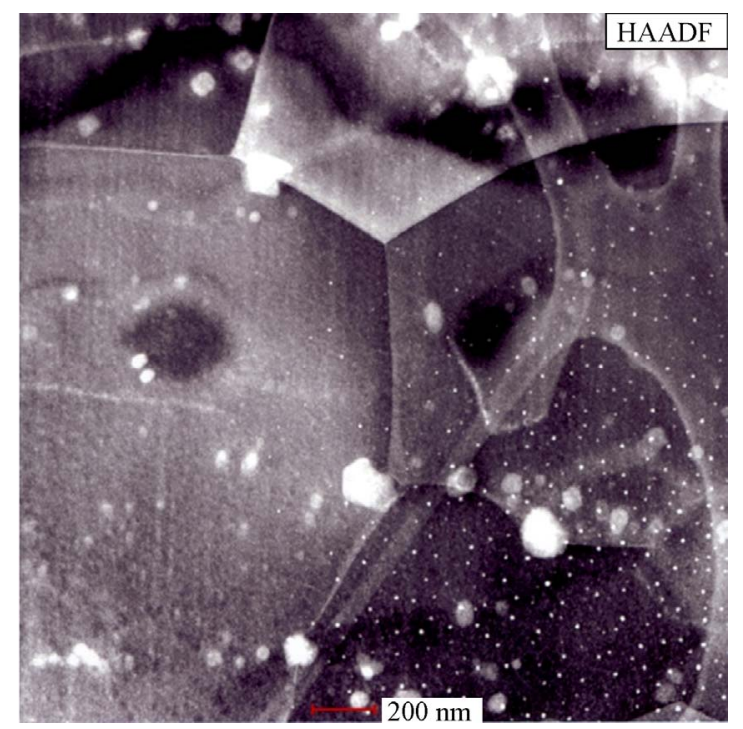

Figure 6. Different types of precipitates are clearly shown in HAADF STEM image. Al3Sc precipitates on the grain boundaries and a homogenous distributes of nano precipitates is observed. 


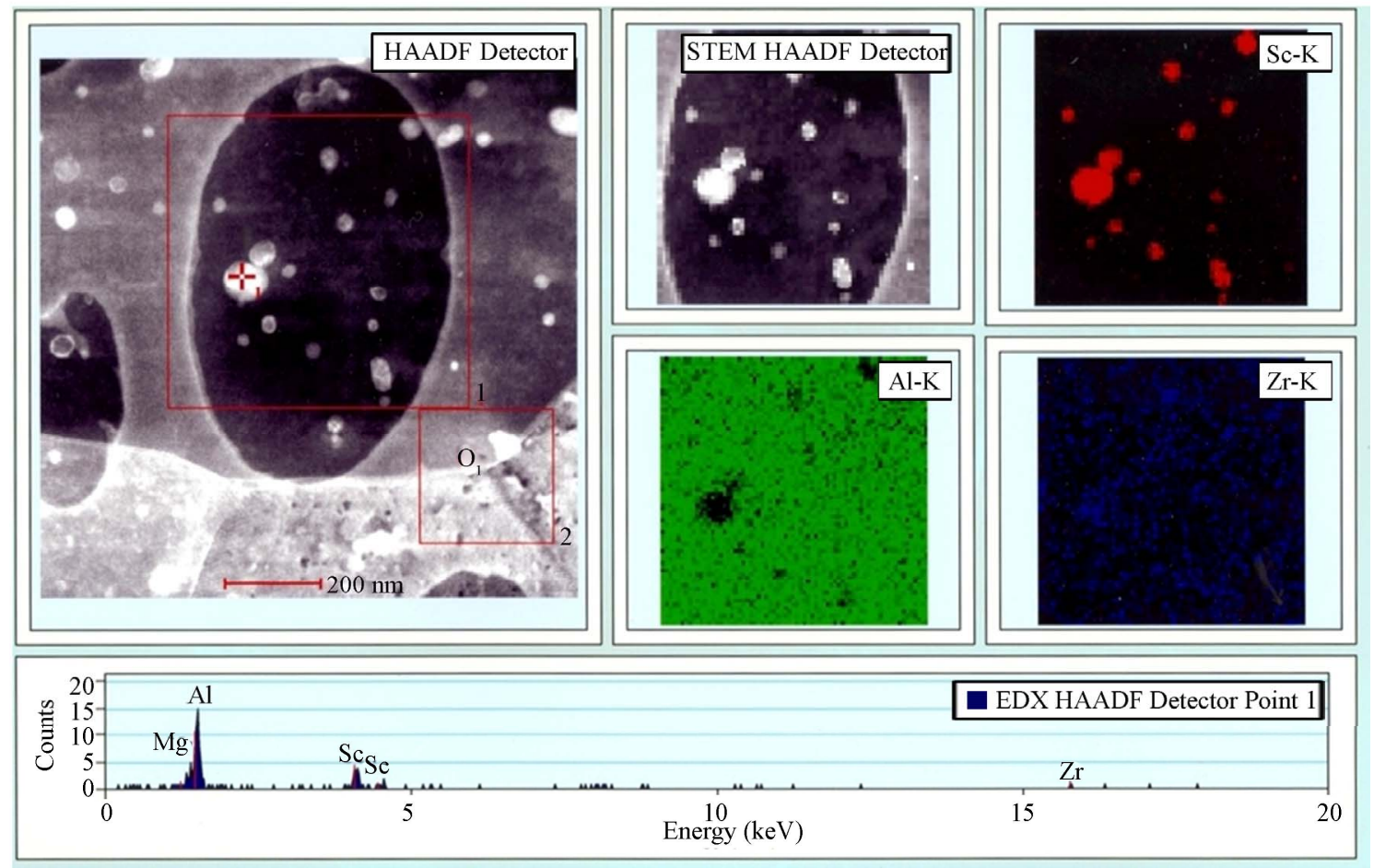

Figure 7. An EDS profile of the precipitates showing the peaks of Aluminum and Scandium thereby indicating the formation of $\mathrm{Al}_{3}\left(\mathrm{Sc}_{1-\mathrm{x}} \mathrm{Zr}_{\mathrm{x}}\right)$ precipitates.

caused by pinning of $\mathrm{Al}_{3} \mathrm{Sc}$ precipitates on the grain boundaries.

6) The Al-Mg-Sc alloys offer an improvement on the

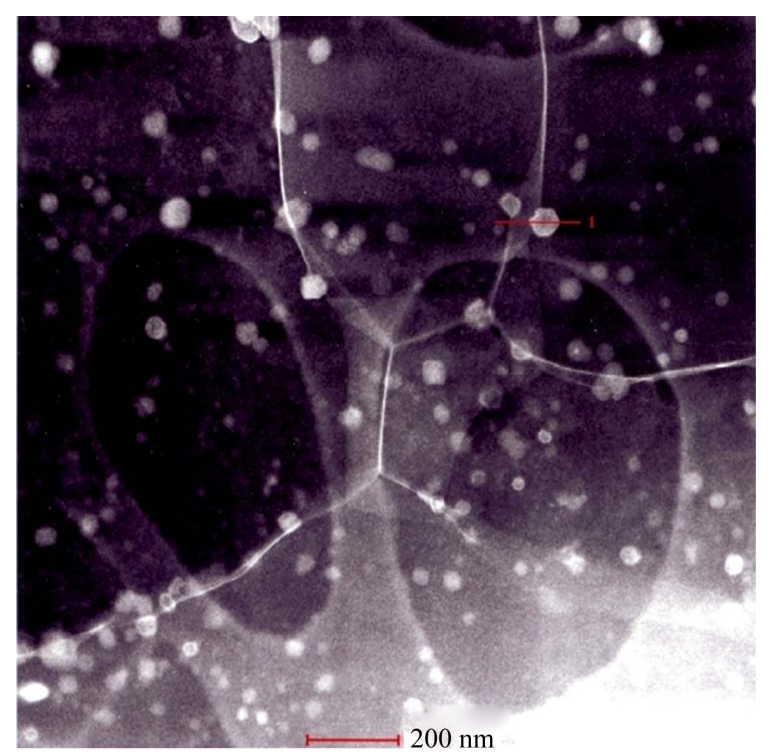

Figure 8. A TEM micrograph showing the pinning of grain boundaries by nano precipitates. this leads to an increase in strengthening effect by the precipitates within narrow range. conventional Al-Mg alloys by offering higher strengths and better corrosion resistance.

\section{Acknowledgements}

The authors appreciate the support and encouragement provided by KFUPM in conducting the above investigations.

\section{REFERENCES}

[1] W. T. Tack, "Aluminum-Scandium Alloys," US Patent 5,597,529, 1997.

[2] M. E. Drits, N. T. Turkina and E. S. Kander, "Structure and Mechanical Properties of Aluminum-Scandium Alloys," In: Rare Earth Metals in Non Ferrous Alloys (Russian), Nauko, Moscow, 1975.

[3] M. E. Drits, L. S. Toropova and Y. U. G Bykov, "Effect of REM on the Mechanical Properties of Aluminum Alloys Containing 6.5\% Mg," Metal Science and Heat Treatment, Vol. 22, No. 10, 1980, pp. 35-37.

[4] M. E. Dritz, S. G. Pavlenko, L. S. Toropova, Y. G. Bykov and L. B. Ber, "Mechanism of Scandium Effect to Increasing Strength and Thermal Stability of Al-Mg Alloys," Doklady Akademii Nauk, SSSR, Vol. 257, No. 2, 1981, pp. 353-356.

[5] M. Song, Y. H. He and S. F. Fang, "Effects of Zr Content on the Yield Strength of an Al-Sc Alloy," Journal of Ma- 
terials Engineering and Performance, Vol. 20, No. 3, 2010, pp. 377-381.

[6] B. Irving, "Scandium Places Aluminum Welding on a New Plateau," Welding Journal, Vol. 76, No. 7, 1997, pp. 53-57.

[7] R. R. Sawtell and C. L. Jensen, "Mechanical Properties and Microstructures of Al-Mg-Sc Alloys," Metallurgy and Materials Transactions, Vol. 21, No. 1, 1990, pp. 421-430. doi:10.1007/BF02782422

[8] M. E. Dritz, L. B. Ber, Y. G. Bykov, L. S. Toropova and G. K. Anastaseva, "Ageing Alloy Al-0.3 at.\% Sc," Physics of Metal and Metallography, Vol. 57, 1984, pp. 118126.

[9] V. L. Elagin, I. V. Zakharov and T. D. Rostova, "Scandium-Alloyed Aluminum Alloy," Nonferrous Metals and Alloys, Vol. 34, No. 1, 1992, pp. 37-45.

[10] N. Blake and M. A. Hopkins, "Constitution and Age Hardening of Al-Sc Alloys," Journal of Material Science, Vol. 20, 1985, pp. 2861-2867. doi:10.1007/BF00553049

[11] Z. Ahmad, "The Properties and Application of ScandiumReinforced Aluminum," JOM Journal of the Minerals, Metals and Materials Society, Vol. 55, No. 2, 2003, pp. 35-39.

[12] ASTM G3-72, "Laboratory Immersion Testing, Book of Annual Standards," ASTM, Columbus, 2002.

[13] ASTM G5-87, "Recommended Practice for Making Potentiostatic and Potentiodynamic Polarization Measurements, Annual Book of Standards," ASTM, Columbus,
2002.

[14] ASTM G5-91, "Recommended Practice for Making Polarization Resistance Measurements, Annual Book of Standards," ASTM, Columbus, 2002.

[15] ASTM G61-86, "Conducting Cyclic Potentiodynamic Polarization Measurements for Localized Corrosion, Annual Book of Standards," ASTM, Columbia, 2002.

[16] Z. Ahmad, "Effect of Velocity on the Corrosion Behavior of Al-3Mg in North Sea Water," Métaux-CorrosionIndustrie, Metaux, 1982.

[17] K. N. Nisanloglu and H. Holtan, "Correlation of the Open-Circuit and Electrochemical Measurements for the Pitting Corrosion of Aluminim in Chloride Media," Metarials and Corrosion, Vol. 30, No. 2, 1979, pp. 105113.

[18] N. V. Yvazovikina, N. A. Krapivka and S. S. Ponomarev, "Kinetics and Mechanism of Scandium Dissolution in Sulfuric Acid Solutions," Russian Journal of Electrochemistry, Vol. 33, No. 9, 1997, pp. 950-957.

[19] N. V. Yvazovikina, S. S. Ponomarev and N. A. Krapivka, "Anode Dissolution and pasSivation D-Transition Metals and Their Alloys in Aqueous Solutions of Electrolytes 2000 hrs," Joint International Meeting of Electrochemical Society, Paris, Vol. 97-2, No. 554, 1997, p. 663.

[20] M. E. Drits, E. J. Kadner and T. V. Dobats, "ScandiumAluminum Interactions in the Al-Rich Side of the Al-Sc System," Russian Metallurgy, Vol. 4, 1973, p. 152. 